\title{
20 ADVANCE CARE PLANNING: THE IMPACT OF LAW AND PUBLIC POLICY
}

10.1136/bmjspcare-2011-000053.20

\author{
S Chapman The National Council for Palliative Care, London, UK
}

Advance Care Planning in England has been advanced through a combination of clinical practice, legislation (the Mental Capacity Act 2005) and public policy (The End of Life Care Strategy 2008 and related regional and local strategies), which carry with them compliance, governance and training requirements. Power has been placed in the hands of the people being cared for, as well as the services and professionals who commission and provide care. This presentation will examine the holistic impact on advance care planning of this multi-levered approach to implementation, and identify the impact of the different levers, separately and collectively. 